\title{
Comparative Study of Corrosion Behaviour of Nickel and Gold Plated Carbon Steels Used as Ornamentals in Saline Environment
}

\author{
Oluwole O. O. , Garus-Alaka W, Ajide O. O
}

Department of Mechanical Engineering, University of Ibadan, Nigeria

\begin{abstract}
This study investigated the corrosion resistance of plated and unplated steels useful as ornamentals in saline environment. Nickel plating of carbon steel was done in watts solution for 25 minutes with a current density of $3 \mathrm{Adm}^{-3}$ at $60^{\circ} \mathrm{C}$. The nickel plated carbon steel was later gold plated for 20 minutes with a current density of $0.2 \mathrm{Adm}^{-3}$ at $50^{\circ} \mathrm{C}$. The plated and unplated carbon steels were immersed in saline environment for 360 hours. Weight loss was taken every 24 hours in order to evaluate corrosion penetration rate (CPR). The results obtained showed that plated carbon steel generally offers a better corrosion resistance than the unplated one. Corrosion of ornamentals is equally gaining importance especially coated ornamentals. The use of nickel for ornamentals is gaining more prominence over silver rising due to its shiny surface and its cost. The use of nickel plated ornamentals just as gold plated ornamentals are being patronized will surely become common place due to affordability for the generality of people. However, the effects of everyday corrosive fluids from kitchen salt and low acidic media on the durability of the coatings need to be established. Carbon steel is the natural substrate used in ornamental coatings. The results also showed that a small thickness of gold plated carbon steel exhibited better corrosion resistance in saline environment. More also, gold plated carbon steel is found to be more suitable and reliable candidate material than nickel plated carbon steel in this environment although with higher costs.
\end{abstract}

Keywords Carbon Steel, Saline, Nickel Plating, Gold Plating, Corrosion

\section{Introduction}

The challenges of corrosion in manufacturing and domestic sectors are enormous. According to Mark (2009), replacing corroded pipeline costs upward of $\$ 643,000$ per kilometer. He explained that manufacturing and inspecting pipelines is vital in the battle with corrosion. Quoting mark, "We are one of the few disciplines in the engineering field that actually works every day to put ourselves out of a job, because once corrosion is eliminated, we will have nothing else to do." The hallmark of his message is that concerted efforts must be made in order to significantly address the problem of corrosion. According to Denny (2004), the total annual estimated cost of corrosion in the United States was approximately \$276billion. The corrosion causes between \$8billion to \$128billion in economic damage per year in the United States alone degrading structures, machines and containers in the oil and gas industry. SPE (2008) stated in their report that Nigeria oil and gas industry suffered greatly between 2000 and 2004. The total pipeline breakage loss fig-

* Corresponding author:

lekeoluwole@gmail.com (Oluwole O. O.)

Published online at http://journal.sapub.org/ijme

Copyright (C) 2012 Scientific \& Academic Publishing. All Rights Reserved ure due to corrosion in 2004 alone is 396,000 metric tons (About four super tankers) while the financial losses is estimated to be \#19.66billions (US \$154.4). About 150-200 thousands bpd of crude oil is said to be lost per day. Corrosion in crude oil systems is one of the most costly problems facing oil companies, which go to great expense to effectively control the problems. Corrodible surfaces are found throughout production, transport and refining equipment. Therefore, the protection of these equipments is critical to the profitability and successful operation of these companies (Becker, 1998).

Carbon steel is a very important class of steels because of its favourable mechanical properties. Unfortunately, corrosion has proved itself as the major enemy deteriorating its cherished mechanical properties. Quite a number of research efforts have been made towards corrosion control and prevention of steel alloys. The corrosion behaviour of mild steel and high steel in various concentrations of nitric acid $\left(\mathrm{HNO}_{3}\right)$, hydrochloric acid $(\mathrm{HCl})$ and perchloric acid $\left(\mathrm{HClO}_{4}\right)$ has been studied by Osarolube et al (2008). The specimens were immersed in the acidic media for 7 days and corrosion rate evaluated using weight loss method. Findings showed that nitric acid environment was most corrosive to both steels because of its oxidizing nature while the least corrosive is hydrochloric acid. It was also deduced that the rate of metal 
dissolution increased with increasing concentration of the corrosion media and exposure time. Corrosion rates of mild steel in all the acidic media studied were found to be higher than that of high carbon steel. Grajcar et al (2010) compared the corrosion resistance of two-new developed high manganese austenitic steels in $1 \mathrm{~N} \mathrm{H}_{2} \mathrm{SO}_{4}$ and $3.5 \% \mathrm{Nacl}$ solutions. The test results of this study showed the low corrosion resistance of high manganese steels in acidic and chloride media. The authors found that both $26 \mathrm{Mn}-3 \mathrm{Si}-3 \mathrm{Al}-\mathrm{Nb}-\mathrm{Ti}$ and $24.5 \mathrm{Mn}-3.5 \mathrm{Si}-1.5 \mathrm{Al}-\mathrm{Nb}-\mathrm{Ti}$ manganese steel alloys are liable to general pitting corrosion especially and more intensively in the sulphuric acid solution. Uhlig and Morill (2006) studied the corrosion of 18-8 Stainless steel in sodium chloride solutions. It was established that under certain conditions, 18-8 stainless steel is likely to fail in contact with sodium chloride solutions through formation of deep pits. The corrosion effect of orange fruit juice has been investigated through the study of the corrosion of carbon steel in citrus sinensis (Badmos and Ajimotokan,2009). Weight loss technique was used in which test coupons with known weight were immersed in the test media which are natural orange juice, orange juice with preservatives and water for a total exposure time of 10days. The experimental results revealed that the corrosiveness of sweet orange juice relative to carbon steel were mainly a function of its acidity. The author concluded that the packed orange juice with preservatives was most corrosive followed by natural orange juice and water respectively. The inhibition of corrosion of mild steel using piper nigrum $\mathrm{L}$ in different acid medium was investigated by Anand and Balasubramanian (2010). The authors studied the corrosion resistance of this mild steel in hydrochloric and sulphuric acid by weight loss method at different time interval at room temperature. The results of this study showed that the corrosion inhibition behaviour of piper nigrum L is higher in sulphuric acid as compared to hydrochloric acid. The conclusion drawn from this work is that piper nigrum $\mathrm{L}$ is a good inhibitor for improving the corrosion resistance of mild steel in sulphuric acid. Many researchers have equally demonstrated the application of electroplating of some steels as one of the reliable corrosion control strategy. Ault (2006) critical review paper considered the use of coatings for corrosion control on offshore oil structures. The author provides an overview of the offshore oil and gas industry, the types of structures coated, the coating used in different zones of the structures and the practical criteria that influences the coating process. Findings from literatures showed that oil and gas production is increasingly becoming an important market for nickel coatings. Oloruntoba et al (2011) research work investigated the effect of current density, bath concentration, bath solution volume and electroplating time on Nickel electroplating of low carbon steel. The results of their findings generally showed that increase in any of these variables will increase the thickness of nickel electrodeposition on low carbon steel. These will in no doubt increase the corrosion resistance characteristics of nickel plated low carbon steels. Oluwole et al in 2009 investigated the corrosion resistance of nickel- plated medium carbon steel and 18-8 stainless steel in cassava fluids (i.e. containing hydrogen cyanide). The work simulated the effect of continuous use of the materials in a cyanide environment where corrosion products are left in place. Low carbon steel sample was nickel electroplated at $4 \mathrm{~V}$ for 35 minutes. The plated sample; the unplated sample and 18-8 stainless steel were then subjected to cassava fluid environment for thirty days. The findings of the authors showed that unplated steel was found to be unsuitable for the fabrication of cassava processing machinery because of the very high corrosion rate.18-8 stainless steel was found suitable for use in this environment. Olorunniwo et al (2010) research study was on the performance evaluation of nickelcoated manganese steel in high-chloride low sulphate seawater environments. Structural manganese steels coated with nickel and unplated ones were tested for corrosion characteristics using weight loss method. It was found that the nickel coat was able to resist corrosion overtime via spontaneous formation of passive oxide films at ambient temperature. The authors concluded from their study that highchloride low sulphate seawater (Polluted) environments are more corrosive than high chloride (Clean) seawater environments. More also; a thicker coat of electrodeposited nickel provides better corrosion resistance through formation of passivating oxide layers at the surface of the steels. It is increasingly becoming important to investigate the corrosion properties of decorative materials. Corrosion of coated ornamentals is really attracting more attention in the fashion industry. A novel kind of three-layer zinciron-cbromium electroplated coating was tested and proven to possess good corrosion protective characteristic as well as acceptable decorative properties (Protsenko and Danilov, 2010). A citric-chloride bath containing Fe (III)-complexes is suggested for electrodeposition of iron intermediate layer on the zinc deposit surface. Due to the low acidity (pH 5) and medium operating temperature $\left(20-30^{\circ} \mathrm{C}\right)$, the electrolyte involved has no a strong etching effect and can be used for direct iron deposition on zinc. A finish chromium layer is deposited from formate-sulfate trivalent bath. The authors observed that zinc layer corrodes through the pores of $\mathrm{Fe}$ and $\mathrm{Cr}$ layers and protects the steel substrate against corrosion. It was evident from the study that the iron and chromium layers decelerate the corrosion rate of zinc. The use of nickel for ornamentals is gaining more prominence over silver rising due to its shiny surface and its cost. The use of nickel plated ornamentals just as gold plated ornamentals are being patronized will surely become common place due to affordability for the generality of people. However, the effects of everyday corrosive fluids from kitchen salt and low acidic media on the durability of the coatings need to be established. Carbon steel is the natural substrate used in ornamental coatings.

\section{Materials and Methods}

The materials, equipments and methods used for experimentation are respectively stated in sections 2.1 and 2.2 


\subsection{Materials and Equipments}

Sections 2.1.1 and 2.1.2 gives a list of materials and equipments used in this research.

\subsubsection{Materials and Equipment used for Nickel plating}

Electroplating tank (Plastic in lined tanks), Carbon steel of dimensions $10 \mathrm{~cm} \times 20 \mathrm{~cm}$ with chemical composition listed in table 1 determined by spectrometric analysis. , Nickel Anode, Drying tray and Electrolyte. The following are the features of the electrolyte used for this study:
i. Nickel Sulphate $(300 \mathrm{~g})$
ii. Nickel Chloride $(30 \mathrm{~g})$
iii. Boric acid $(40 \mathrm{~g})$
iv. Nickel brightener $(30 \mathrm{~g})$

\subsubsection{Materials and Equipments used for Gold Plating}

Rectifier, Plating tank, Gold potassium cyanide (30g), Gold metal anode (12.5g) and Nickel plated Mild steel samples (weight of $3.3 \mathrm{~g}$ and Area of $4.56 \mathrm{~cm}^{2}$ ).

\subsection{Methods}

\subsubsection{Chemical Analysis}

The carbon steel used was procured from FIIRO (Federal Industrial Institute of Research, Oshodi), Lagos state. The chemical analysis of the carbon steel was done at Universal Steels Nigeria Ltd., Ikeja, Lagos state.

\subsubsection{Experimental Procedures for Plating Carbon Steel}

A rubber lined tank was cleaned and filled approximately with two-third capacity of clean water. After heating the water to 60 to $70^{\circ} \mathrm{C}\left(140\right.$ to $\left.160^{\circ} \mathrm{F}\right)$, the required weight of prepared Nickel Salts was added slowly and thoroughly stirred. When dissolution of the prepared Nickel Salts was completed, the bath was then diluted with clean water of approximately $5 / 6$ ths of the final required volume. At this stage, the solution was purified to remove any traces of metallic impurity or organic contamination before the addition of the brightener additives.

The base metal $(10 \mathrm{~cm} \times 20 \mathrm{~cm})$ was polished and the plastic in lined tank was hot washed with dilute acid and properly rinsed out with cold water (to dilute the remains of the acid clogged inside the plating tank).Polished base metal $(10 \mathrm{~cm} \times 20 \mathrm{~cm})$ was suspended with wires and later pickled in an hydrochloric acid (this is called acid cleaning of work piece). Carbon steel samples were immersed in tanks of dilute hydrochloric cleaning solutions to remove dirt and solid soil from them. The weight of sample was taken before the treatment of the sized polished specimen .This was properly rinsed in water and anodically cleaned in order to avoid drag out of the electrolyte on the material sample. The Nickel plating was done for 25 minutes at a temperature of $60^{\circ} \mathrm{C}$ and constant current density of $0.3 \mathrm{~A} / \mathrm{dm}^{3}$. After the specimen was removed from the plating tank, it was immersed into de-ionised water to avoid drag out and clogging of electrolyte on specimens. Material Sample's final weight was determined in order to know the mass of the electrolyte deposited on the work piece. This helped in determining the thickness of the Nickel plating of the sample carbon steel used in this study. The Nickel plated carbon steel was cut into three pieces of dimension $24 \mathrm{~cm} \times 1.9 \mathrm{~cm}$. These three pieces were used in carrying out the gold plating experiments. A little pre-treatment was done, due to the Nickel undercoat that has been done on base-metal. Proper hammering and straightening was carried out on these pieces to give proper edging and smoothing. This was done in order to avoid blur and hole on the work pieces which can later result to corrosion and instability of electrolyte on work pieces. This was followed by thorough washing of the Nickel coated samples in water and then caustic soda in order to dissolve unwanted agents like hammering and working particles on the work pieces that can interfere with the results of the experiment. After the clogs were dissolved away, the work pieces were suspended into the electroplating tank containing Gold potassium cyanide $(30 \mathrm{~g})$, Gold metal anode $(12.5 \mathrm{~g})$ and Nickel plated work pieces (weight of $3.3 \mathrm{~g}$ and Area of $4.56 \mathrm{~cm}^{2}$ ). The samples were electroplated for 20 minutes to give enough coating thickness. All these specimens were quickly dipped in water immediately they were removed from the bath and later displayed in the drying tray for cooling. Weight of each piece was taken by scout pro-balance to know the mass of gold material deposited on the Nickel plated steels.

Table 1. Chemical Analysis of Carbon Steel

\begin{tabular}{|c|c|c|c|c|c|c|c|c|c|c|c|}
\hline \multicolumn{2}{|c|}{ Run } & $\mathrm{C}$ & \multicolumn{2}{|c|}{$\mathrm{Si}$} & $\mathrm{S}$ & \multicolumn{2}{|c|}{$\mathrm{P}$} & $\mathrm{Mn}$ & \multicolumn{2}{|c|}{$\mathrm{Ni}$} & $\mathrm{Cr}$ \\
\hline \multicolumn{2}{|c|}{$(1)$} & .3397 & \multicolumn{2}{|c|}{0.2191} & 0.0573 & \multicolumn{2}{|c|}{0.0620} & 0.8294 & \multicolumn{2}{|c|}{0.0960} & 0.1242 \\
\hline \multicolumn{2}{|l|}{ (2) } & .3426 & \multicolumn{2}{|c|}{0.2204} & 0.0605 & \multicolumn{2}{|c|}{0.0597} & 0.8343 & \multicolumn{2}{|c|}{0.0961} & 0.1245 \\
\hline \multicolumn{2}{|c|}{ Avg } & 0.3411 & \multicolumn{2}{|c|}{0.2198} & 0.0589 & \multicolumn{2}{|c|}{0.0609} & 0.8318 & \multicolumn{2}{|c|}{0.0960} & 0.1244 \\
\hline Mo & V & $\mathrm{Cu}$ & W & As & Sn & Co & $\mathrm{A} 1$ & $\mathrm{~Pb}$ & $\mathrm{Ca}$ & $\mathrm{Zn}$ & $\mathrm{Fe} \%$ \\
\hline 0.0188 & 0.0057 & 0.2066 & 0.0035 & 0.0056 & 0.0252 & 0.0088 & -0.0007 & 0.0001 & 0.0001 & 0.0035 & 97.9951 \\
\hline 0.0191 & 0.0058 & 0.2077 & 0.0035 & 0.0059 & 0.0262 & 0.0088 & -0.0007 & -0.0000 & 0.0001 & 0.0038 & 97.9816 \\
\hline 0.0189 & 0.0058 & 0.0189 & 0.0035 & 0.0058 & 0.0257 & 0.0088 & -0.0007 & 0.0001 & 0.0001 & 0.0036 & 97.9883 \\
\hline
\end{tabular}




\subsubsection{Weight Loss Measurement and Corrosion Penetration Rate (CPR)}

The unplated, Nickel plated and Gold plated (with Nickel underlay) carbon steels coupons were immersed in $0.5 \mathrm{~mol}$ $\mathrm{dm}^{-3}$ of $100 \mathrm{ml}$ saline environment for a period of 360 hours (15days).The corrosion coupons were removed from the corrosion environment with the aid of a tong. These were then properly cleaned in distilled water and dried with cotton wool. The dried samples were weighed with the electronic digital weighing balance and recorded. Weight loss measurements of coupons were recorded at interval of 24 hours. The corrosion penetration rate (CPR) was calculated from weight loss analysis using the equation (1)

$$
C P R=\frac{87.6 \mathrm{~W}}{\rho A t}
$$

Where;

$$
\begin{gathered}
C P R-\text { Corrosion Penetration Rate in } \mathrm{mm} / \mathrm{yr}, \\
\text { W - Weight Loss in } \mathrm{mg} \\
\rho \text { is density in } \mathrm{g} / \mathrm{cub} . \mathrm{cm}, \\
\text { A is Area of exposed specimen in } \mathrm{cm}^{2} \\
\text { t is exposure time in } \mathrm{hr} .
\end{gathered}
$$

\section{Results and Discussion}

\subsection{Results}

Table 2. Nickel Plating Parameters

\begin{tabular}{|c|c|c|c|c|}
\hline $\begin{array}{c}\text { Weight } \\
\text { (initial) }(\mathrm{g})\end{array}$ & $\begin{array}{c}\text { Time in solu- } \\
\text { tion }(\mathrm{min})\end{array}$ & $\begin{array}{c}\text { Weight } \\
\text { (final) }(\mathrm{g})\end{array}$ & $\begin{array}{c}\text { Temperature } \\
\left({ }^{\circ} \mathrm{C}\right)\end{array}$ & $\begin{array}{c}\text { Current } \\
\mathrm{A} / \mathrm{dm} 3\end{array}$ \\
\hline 281.5 & 25 & 325.7 & 60 & 3.0 \\
\hline
\end{tabular}

Table 3. Gold Plating Parameters

\begin{tabular}{|c|c|c|c|c|}
\hline $\begin{array}{c}\text { Weight } \\
\text { (initial) }(\mathrm{g})\end{array}$ & $\begin{array}{c}\text { Time in solu- } \\
\text { tion }(\mathrm{min})\end{array}$ & $\begin{array}{c}\text { Weight } \\
(\mathrm{final})(\mathrm{g})\end{array}$ & $\begin{array}{c}\text { Temperature } \\
\left({ }^{\circ} \mathrm{C}\right)\end{array}$ & $\begin{array}{c}\text { Current } \\
\mathrm{amp} / \mathrm{dm}^{3}\end{array}$ \\
\hline 15.4 & 20 & 15.9 & 50 & 0.2 \\
\hline
\end{tabular}

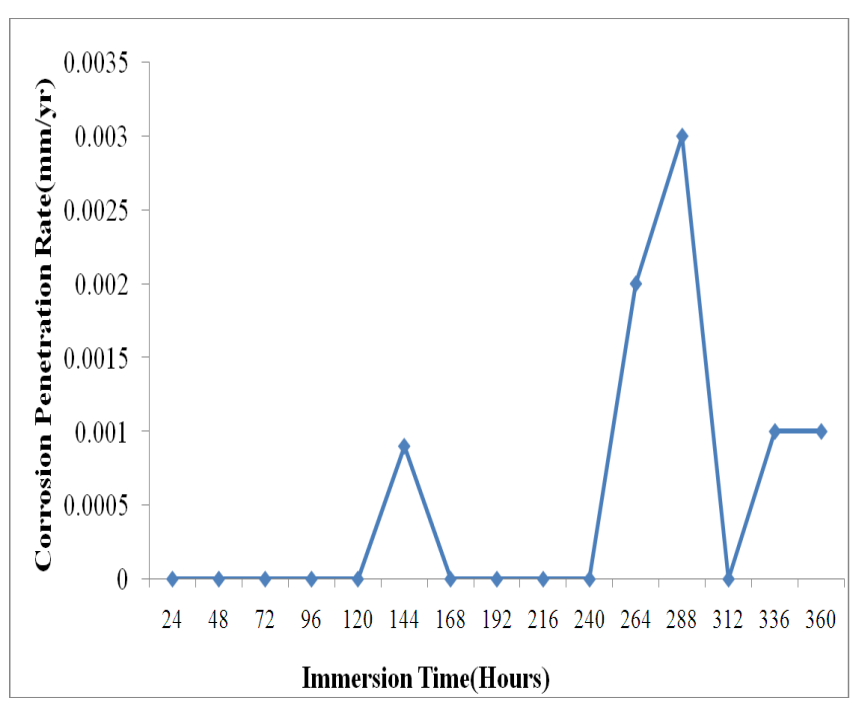

Figure 1. Corrosion Penetration Rates of Carbon Steel in Saline Environment

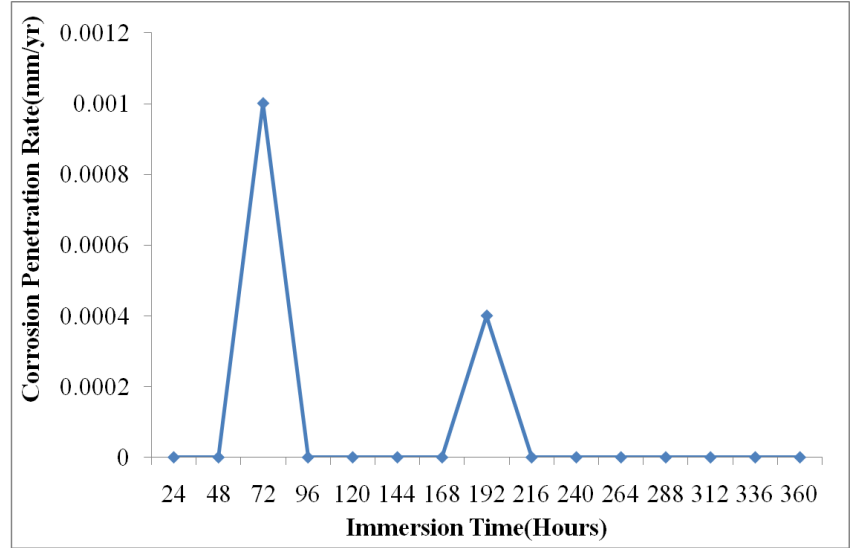

Figure 2. Corrosion Penetration Rates of Nickel Plated Carbon Steel in Saline Environment

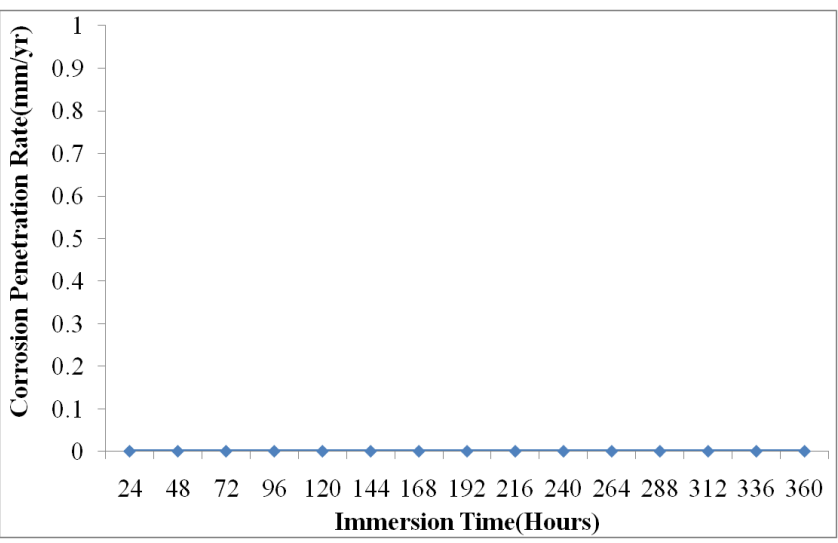

Figure 3. Corrosion Penetration Rates of Gold Plated Carbon Steel (with Nickel Underlay) in Saline Environment

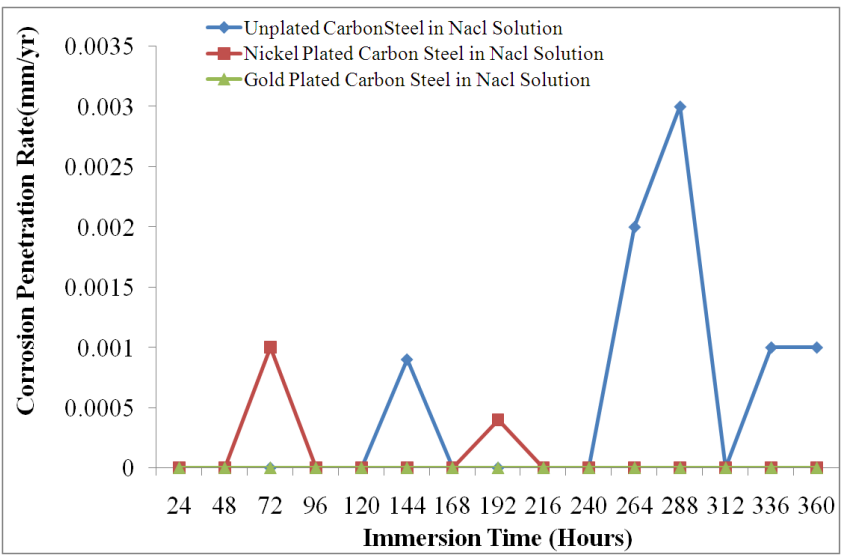

Figure 4. Chart Displaying Different Corrosion Penetration Rates of Unplated and Plated Carbon steels in Saline Environment

\subsection{Discussions}

Tables 2 and 3 gives the current density, plating time and increase in weight during Nickel and gold plating of carbon steels. An increase in weight of $44.2 \mathrm{~g}$ and $0.5 \mathrm{~g}$ were obtained for nickel and gold plated carbon steels respectively. Fig.1 describes the corrosion behaviour of the unplated carbon steel in 0.5 moldm $^{-3} \mathrm{Nacl}$ medium during a 360 hours immersion. The carbon steel coupons do not experience corrosion in the first 120 hours. The unplated carbon steel started experiencing corrosion in the $121^{\text {st }}$ hour. The corrosion rate 
increases to $9 \times 10^{-4} \mathrm{~mm} / \mathrm{yr}$ at the $144^{\text {th }}$ hour. The CPR sharply reduces to an approximate $0 \mathrm{~mm} / \mathrm{yr}$ in the $168^{\text {th }}$ hour. Between 168 hours and 240 hours, the unplated carbon steel maintained this approximate $0 \mathrm{~mm} / \mathrm{yr}$ of CPR. The reason for this is due to the formation of passivating film on the sample material. The passive film formed provides a protective layer on it thereby hindering the corrosion process. Unexpectedly, the corrosion rate picked up again in the $241^{\text {st }}$ hour and maintained an increase until the CPR reached $2 \times 10^{-3} \mathrm{~mm} / \mathrm{yr}$ and $3 \times 10^{-3} \mathrm{~mm} / \mathrm{yr}$ in the $264^{\text {th }}$ and $288^{\text {th }}$ hours respectively. The breakage of the passive film is greatly responsible for this renewed corrosion. From this peak, the corrosion rate reduced to $0 \mathrm{~mm} / \mathrm{yr}$ just for a while and renew its increase in corrosion rate between 336 hours and 360 hours. In the final analysis of fig 1, the unplated carbon steel showed a highly significant corrosion penetration rates in saline medium. In the few instances where it experienced an approximate no corrosion, the CPR often peaked up again irregularly. No doubt, unplated carbon steel is not suitable in saline environment at least for the duration of 360 hours of the study.

Fig.2 illustrates the corrosion of nickel plated carbon steel in 0.5 moldm$^{-3}$ saline environment as for the unplated carbon steel. Between 48 hours and 216 hours, the nickel plated carbon steel experienced a significant corrosion. The CPR is $1 \times 10^{-3} \mathrm{~mm} / \mathrm{yr}$ at the $72^{\text {nd }}$ hour and $4 \times 10 \mathrm{~mm} / \mathrm{yr}$ at the $192^{\text {nd }}$ hour. A passive film which was formed at the $216^{\text {th }}$ hour remained stable throughout the study periods. This explains why the CPR remained at $0 \mathrm{~mm} / \mathrm{yr}$ between 216 hours and 360 hours. A protective layer of nickel oxide $\left(\mathrm{NiO}_{2}\right)$ is highly suspected to have been formed. The chart in fig. 2 shows that nickel plated carbon steel experienced little or no corrosion if used in this medium for a long period of time. However, it thus experienced a significant corrosion rate in the first few days of immersion in saline medium. This may be due to the fact that a protective layer which provides a shield against corrosion is being formed during this period.Fig. 3 shows the corrosion behaviour of gold plated carbon steel in 0.5 moldm $^{-3}$ saline environment. The gold plated carbon steel with nickel underlay does not experience any CPR throughout the period under study. This no doubt is due to passive nature of gold in the galvanic series and formation of highly stable passive film on the material. This clearly showed that gold electroplated carbon steel is a good candidate material in saline environment.

Fig.4 gives a comparative analysis of the corrosion characteristics of the unplated and plated carbon steels (Nickel plated and Gold plated carbon steels) in saline environments. The chart shows that the unplated carbon steel has the highest CPR of $3 \times 10^{-3} \mathrm{~mm} / y r$ at the $288^{\text {th }}$ hour. Nickel plated carbon steel has a better corrosion resistance than the unplated carbon steel. The highest CPR obtained for nickel plated carbon steel is $9 \times 10^{-4} \mathrm{~mm} / \mathrm{yr}$ at the $72^{\text {nd }}$ hour. It only experienced corrosion degradation in the first 8 days after which a passive film formed tremendously improves its corrosion resistance.Fig.4 clearly shows that gold plated carbon steel has the best corrosion resistance in saline en- vironment. The result shows that the best material for construction of ornamentals that will be used in salty medium is gold plated carbon steel. Nickel plated carbon steel can also be used as an alternative material where the costs of gold plating is considered to be a constraint.

\section{Conclusions}

This study has established that unplated carbon steel is unsuitable in saline environment due to its high corrosion penetration rates. Nickel and gold plated carbon steels are highly corrosion resistance and therefore suitable for use as plating for ornamentals in saline environment. Gold plated carbon steel is the most suitable and reliable candidate material in this medium although with higher costs.

\section{REFERENCES}

[1] Anand, B. and Balasubramanian, V.2010. A Comparative Study on Corrosion Inhibition of Mild Steel Using Piper Nigrum L in Different Acid Medium. E-Journal of Chemistry World Wide Web Publications. 7(3), pg. 942-946. ISSN: 0973-4945.

[2] Ault, J.P.2006.The Use of Coatings for Corrosion Control on Offshore Oil Structures. Journal of Protective Coatings and Linings, Vol.23, Issue 4.Technical Publishing Company.

[3] Badmos, A.Y. and Ajimotokan, A.A.2009.The Corrosion of Mild Steel in Orange Juice Environment. A technical Report With No: 2009-02 Written by Badmos and Ajimotokan of the Department of Mechanical Engineering, University of Ilorin, Nigeria.

[4] Becker, J.R.1998.Corrosion and Scale Handbook, Penwell Publishing Company, United Kingdom.

[5] Oloruntoba D., Eghwubare.O. And Oluwole.O. 2011. 'Effect of Some Process Variables on Nickel Electroplating of Low Carbon Steel', Leonardo Electronic Journal of Practices and Technology, Technical University of Cluj-Napoca, Romania 10(18), 79-94.

[6] Denny, J.2004.Principles and Preventions of Corrosion, Upper Saddle River, New Jersey Prentice Hall. ISBN 0-13-359993-0.

[7] Grajcar, A.; Kolodziej, S. and Krukiewic, Z.2010. Corrosion Resistance of High-Manganese Austenitic Steels. International Scientific Journal Published Monthly by the World Academy of Materials and Manufacturing Engineering. Volume 41, Issue 2, pg77-84.Archives of Materials Science and Engineering.

[8] Mark, B.2009.The Fight against Corrosion. Mark Byerly was the President of NACE International in 2009-2010 Term. www.nace.org

[9] Olorunniwo,O.E.;Atanda,P.O.;Akinluwade,K.J.;Adetunji, A. R. and Oluwasegun, K.M.2010.Performance of Nickel-Coated Manganese steel in High-Chloride Low-Sulphate Seawater Environments. Journal of Minerals and Materials Characterization and Engineering. Vol.9.No.10.pp. 879-886. 
jmmce. org, printed in the USA.

[10] Oluwole, O.O.; Atanda, P.O.; Odekunbi, O.A. and Odegbaju, E.2009.Corrosion Behaviour of 18-8 Stainless Steel and Nickel-Plated Low-Carbon Steel in Cassava fluid. Journal of Minerals and Materials characterization and Engineering, Vol.8, No.10.pp803-811-2009.jmmce.org, printed in the USA.

[11] Osarolube, E.; Owate, I.O. and Oforka, N.C.2008. Corrosion Behaviour of Mild and High Carbon Steels in Various Acidic Media. Scientific Research and Essay.Vol.3 (6), pg.224-228. ISSN-1992-2248. http : //www.academicjournals.org

[12] Protsenko,V.S. and Danilov,F.I.,2010.The Corrosion- Pro- tective Traits of Electroplated Multilayer Zinc-Iron- Chromium Deposits. Sample records for conventional decorative chromium from worldscience.org. Worldscience.org are maintained by the U.S. Department of Energy's Office of Scientific and Technical Information as the operating Agent for Worldscience Alliance.

[13] SPE.2008.Society of Petroleum Engineers Journal, Volume 8, Philips Publishing Inc. Company, pg 35.

[14] Uhlig, H.H. and Morill.2009.Corrosion of 18-8 Stainless Steel in Sodium Chloride Solutions .Department of Chemical Engineering, Massachusetts, Institute of Technology, Cambridge. 